\title{
Panorama internacional e status de adoção da ISO 19650
}

International overview and adoption status of ISO 19650

\author{
Aline Prado Costa \\ Universidade Estadual de Campinas | Campinas | Brasil | a233484@dac.unicamp.br
}

Katrícia Milena Almeida Corrêa

Universidade Federal do Amapá | Macapá | Brasil | katriciacorrea@unifap.br

Erica de Matos Miranda

Universidade Estadual de Campinas | Campinas | Brasil | e155254@dac.unicamp.br

Regina Coeli Ruschel

Universidade Estadual de Campinas | Campinas | Brasil | ruschel@unicamp.br

\section{Resumo}

A ISO 19650 consiste em uma série normativa, de escala internacional, com ênfase em Building Information Modeling (BIM). Esta série de normas tem sido bem recebida entre os países membros da Organização Internacional de Normalização (International Organization for Standardization - ISO), porém, para que a aplicação efetiva dessa série ocorra, se faz necessário um processo específico de adoção. Este artigo visa caracterizar o contexto internacional do processo de adoção das partes 1 e 2 da ISO 19650, lançadas em 2018. A partir de um levantamento feito junto às plataformas online de organizações normativas de nível nacional, além de um levantamento bibliográfico, constatou-se que o setor governamental impulsionou a aplicação da norma na maior parte dos países pesquisados e que o grau de adoção da tecnologia BIM não determina o status de adoção da referida norma.

Palavras-chave: BIM. Série ISO 19650. Normalização. Adoção.

\begin{abstract}
ISO 19650 consists of an international normative series with an emphasis on Building Information Modeling (BIM). This series of standards has been well received among member countries of the International Organization for Standardization (ISO), however, for the application of this series to occur, a specific adoption process is necessary. This article seeks to describe the international context of the process of adopting parts 1 and 2 of ISO 19650 released in 2018. From a survey carried out on online platforms of national regulatory organizations, in addition to a bibliographic survey, it was found that the government sector boosted the application of the standard in most countries surveyed, and that the degree of adoption of the BIM technology does not determine the status of adoption of that standard.
\end{abstract}

Keywords: BIM. ISO 19650 series. Standardization. Adoption.

\section{INTRODUÇÃO E FUNDAMENTAÇÃO}

É evidente que a tecnologia Building Information Modeling (BIM) tem sido disseminada cada vez mais internacionalmente. Pesquisas acadêmicas apontam que houve um

Como citar:

COSTA, A. P.; CORRÊA, K. M. A.; MIRANDA, E. de M.; RUSCHEL, R. C. Panorama internacional e status de adoção da ISO 19650. In: SIMPÓSIO BRASILEIRO DE TECNOLOGIA DA INFORMAÇÃO E COMUNICAÇÃO NA CONSTRUÇÃO, 3., 2021, Uberlândia. Anais [...]. Porto Alegre: ANTAC, 2021. p. 1-12. Disponível em:

https://eventos.antac.org.br/index.php/sbtic/article/view/599. Acesso em: 3 ago. 2021. 
aumento expressivo na adoção do BIM nos principais mercados da Arquitetura, Engenharia e Construção (AEC) [1] [2]. Este cenário vem sendo impulsionado pelo lançamento de iniciativas, protocolos e normas internacionais sobre BIM, conduzido por ações governamentais e pela indústria [1]. Nesta perspectiva, o rápido desenvolvimento BIM, bem como a integração deste às novas tecnologias têm sido mais comuns na última década, resultando, também, no surgimento de novas direções de pesquisa, dentre elas, a que se refere à normalização [2].

O desenvolvimento da ISO 19650 caracteriza um importante passo para a adoção da tecnologia BIM nos países como um processo mais integrado, pois busca estabelecer os tipos de requisitos necessários sobre as informações de ativos ao longo das fases de seu ciclo de vida (projeto, construção e operação) [3]. Além disso, sugere quais as partes envolvidas nesse processo e o modo de comunicação entre elas. Neste sentido, o artigo apresenta a seguinte questão de pesquisa: Qual o panorama internacional de adoção da ISO 19650? A investigação apresentada neste artigo teve por objetivo caracterizar globalmente o processo de adoção das partes 1 e 2 da ISO 19650, a partir de informações encontradas nas organizações normativas dos países pesquisados. Complementando a discussão com base em referências relevantes para a temática, [03], [10], [11], aponta-se quais seriam as iniciativas incentivadoras da implantação da norma.

\section{HISTÓRICO DA ISO 19650}

A ISO $19650^{1}$ [4] é um norma internacional para gerenciamento de ativos através da utilização da tecnologia BIM e de processos colaborativos para uma administração eficaz de informações nas fases de entrega e operação [3]. A utilização dessa norma é direcionada a todos envolvidos na contratação, projeto, construção e operação do ativo. O registro de surgimento da ISO 19650 deu-se com o início de um grupo de trabalho para o BIM Level 2 no Reino Unido [5]. Este grupo de trabalho, com aprovação em 2016, foi impulsionado pelo governo do Reino Unido para garantir a inovação e integração entre os projetos, promovendo uma troca coordenada de informações entre as partes do sistema e do projeto [6].

Os registros de adoção de BIM no Reino Unido em 2015 eram de 48\% e em 2017 passou a ser de $62 \%$, após adoção de BIM Level 2 obrigatório nos projetos governamentais [7]. A adoção de BIM no Reino Unido já ocorria a partir da criação da normativa BS 1192, surgida em 2007 no Reino Unido, com a ideia de organizar e facilitar a comunicação dos processos no BIM. Via-se a dificuldade em gerir os processos e as informações, sendo assim, foi criada uma normativa que pudesse pautar esses processos.

Em 2013, foi elaborada a PAS $1192^{2}$, uma especificação de acesso público para gerenciamento de informações para a fase de capital/entrega de projetos de

\footnotetext{
${ }^{1}$ Nomeada como: Organization and digitization of information about buildings and civil engineering works, including building information modelling (BIM) - Information management using building information modelling [4]

${ }^{2}$ Nomeada como: Specification for information management for the capital/delivery phase of construction projects using building information modelling
} 
construção usando modelagem de informações de construção [8]. As PAS $^{3}$ são especificações disponíveis ao público desenvolvidas de forma acelerada para atender a uma necessidade imediata do mercado Britânico de acordo com as diretrizes estabelecidas pela Instituição Britânica de Normalização (British Standards Institution - BSI). Com o passar dos anos, estas normativas começaram a ser muito utilizadas e difundidas, despertando o interesse de outros países em utilizar a norma. Com isso, surge a necessidade de criar uma normativa internacional, onde tivesse os parâmetros da utilização de BIM, sem as características específicas do Reino Unido. Assim, a PAS 1192 foi a base para a ISO 19650 e por ela, até o momento, parcialmente substituída.

Desde o início, reconheceu-se o BIM como um caminho inovador para se atuar na construção, e que as tecnologias e processos BIM poderiam transcender fronteiras. Neste prisma, o Reino Unido, a partir da pressão governamental, liderou o desenvolvimento de BIM com o objetivo de internacionalizar a tecnologia, compartilhando conhecimento em nível global [5], exercendo, inclusive, grande influência na adoção macro de BIM na América Latina [9].

Embora o Reino Unido tenha dado o impulso, a série ISO 19650 é genuinamente internacional, elaborada a partir de um consenso entre os países participantes [3]. A ISO 19650 representa um alinhamento normativo para se expandir internacionalmente o BIM, visando alcançar um patamar onde todos começarão a discutir projetos em uma linguagem universalmente padronizada [10].

A British Standards Institution (BSI) observou que durante o processo de desenvolvimento da ISO 19650, as normas europeias passaram a despertar o interesse de outros países, como do Japão e da Austrália [3]. Cabe destacar que as normas ISO eram cada vez mais adotadas como um padrão europeu. Este fato traz consigo a relevância da ISO enquanto instituição de normalização internacional, pois suas normas são amplamente utilizadas por empresas, governos e organizações em âmbito global.

Após o processo de elaboração da série ISO, o Reino Unido passa a adotá-la em 2018. Seus ativos realizados antes deste período, que utilizaram as normativas BS $1192 \mathrm{e} / \mathrm{ou}$ PAS 1192, passam apenas por um processo de readequação. O processo é considerado simples visto que a ISO 19650 tem os princípios da séria UK 1192. A ISO 19650, permite que cada país elabore um anexo com características importantes de sua região e informações locais, para que a ISO seja mais bem adequada ao país de adoção da norma [11].

Atualmente a ISO 19650 é dividida em 6 partes, sendo que as partes 4 e 6 ainda estão em desenvolvimento e as outras já concluídas. A linha do tempo da série ISO 19650 é representada na Figura 1.

\footnotetext{
${ }^{3}$ Publicly Available Specification
} 
Figura 1: Lançamento das partes da série ISO 19650 nos últimos anos

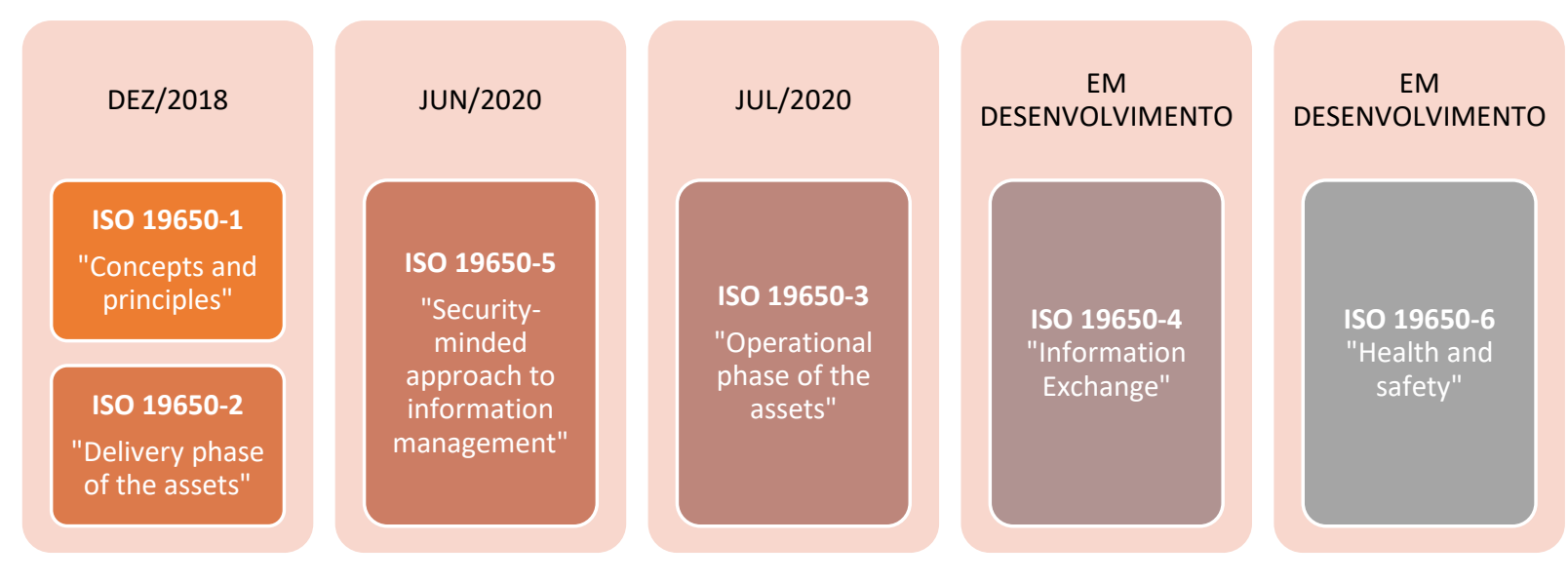

Fonte: as autoras.

\section{MÉTODO}

A pesquisa é exploratória, desenvolvida como um levantamento. $O$ universo de estudo do levantamento foram os países com difusão do BIM listados pelo BSI em palestra recente [12] e caracterizado no mapa da Figura 2, cuja coloração representa os qualificadores de adoção do BIM: maduro, amadurecendo, adoção rápida, adoção lenta e imaturo.

Identificada a amostra, foi feito um estudo diretamente sobre a ISO 19650 nos sites das organizações normativas de cada país. 0 processo de caracterização da adoção da norma considerou os status "aplicando texto original", "traduzido/aplicando", "desenvolvendo anexo", "traduzindo", e "N.I. (Não Identificado)". É importante destacar que essas definições de status presentes nos resultados se referem sempre às partes 1 e 2 da ISO 19650, visto que as partes 3 e 5 foram lançadas recentemente e as partes 4 e 6 ainda estão em elaboração.

Em complementação, foi também realizada uma pesquisa bibliográfica com o termo "ISO 19650". A pesquisa bibliográfica permitiu identificar a força de motivação para a adoção, podendo ser de origem governamental ou privada. As informações encontradas foram organizadas no quadro do Apêndice $A$. 


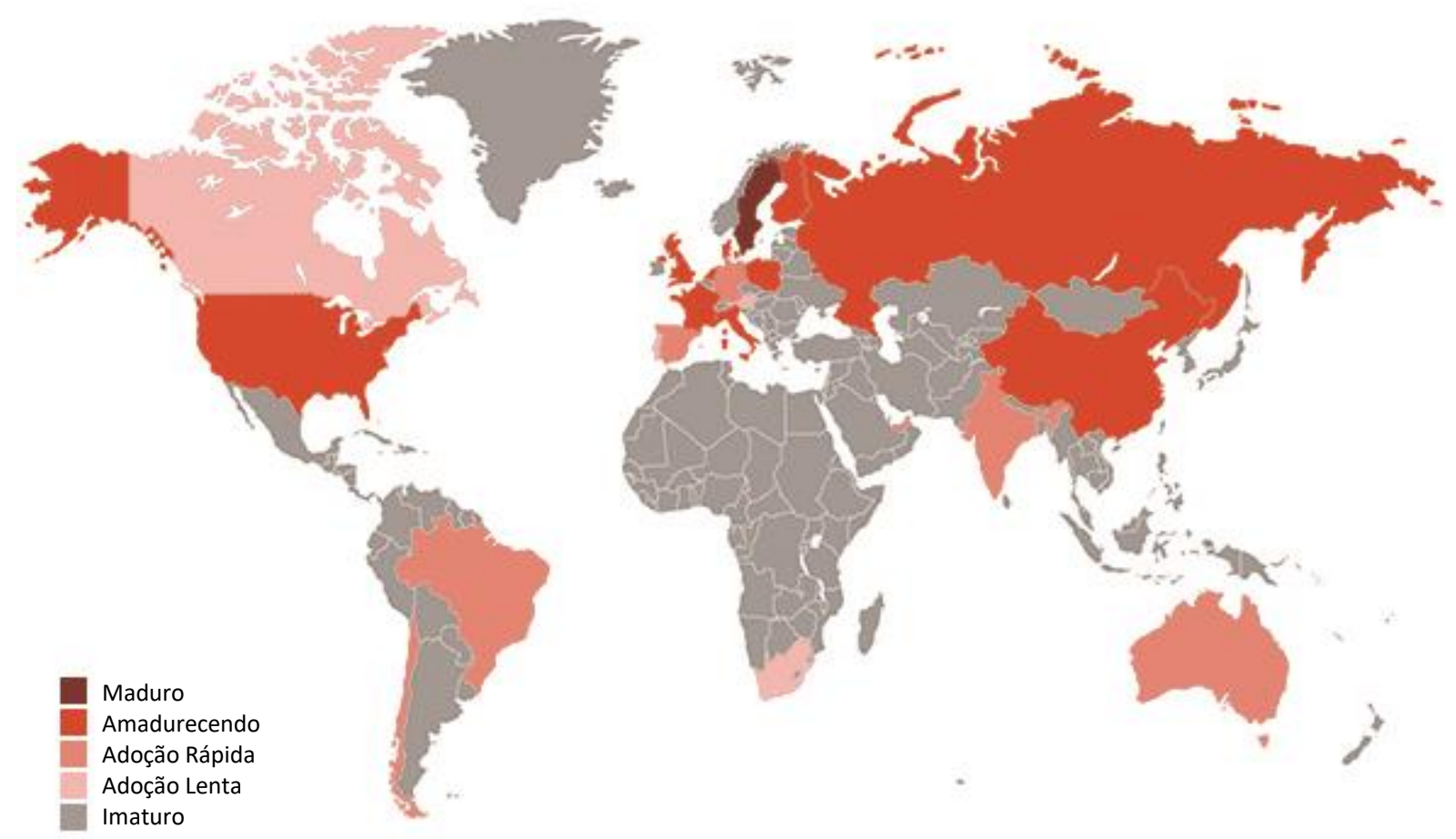

Fonte: adaptado pelas autoras [12].

\section{RESULTADOS E DISCUSSÃO}

Muitas pesquisas estão sendo realizadas e conduzidas por diferentes países para apoiar a adoção internacional do BIM. Algumas iniciativas estão sendo impulsionadas pelo setor governamental (Europa e Ásia) [10] e outras pelo setor privado (EUA, Austrália, Canadá). No Apêndice, o Quadro 1 sumariza os dados coletados, que serviu de base para o mapeamento apresentado neste estudo. No Quadro 1 constam as informações sobre as organizações normativas desses países, o status de adoção da norma ISO 19650 e as respectivas fontes para acesso e compra das normas nos sites nacionais oficiais. Destacam-se, ainda, as iniciativas para a implementação da norma.

\section{ORGANIZAÇÕES NORMATIVAS}

A compreensão sobre as organizações normativas e os diferentes níveis sobre os quais elas atuam, é imprescindível para a discussão das informações geradas. A BSI é um organismo de normalização de nível nacional, pertencente ao Reino Unido. Já o Comitê Europeu de Normalização (European Committe for Standardization - CEN) é uma das três organizações de nível regional atuantes na Europa, enquanto a Organização Internacional de Normalização (International Organization for Standardization - ISO) é uma organização internacional, não-governamental. A hierarquia existente entre essas organizações é expressa no esquema representado na Figura 3. 
Figura 3: Mapa de adoção do BIM em contexto internacional

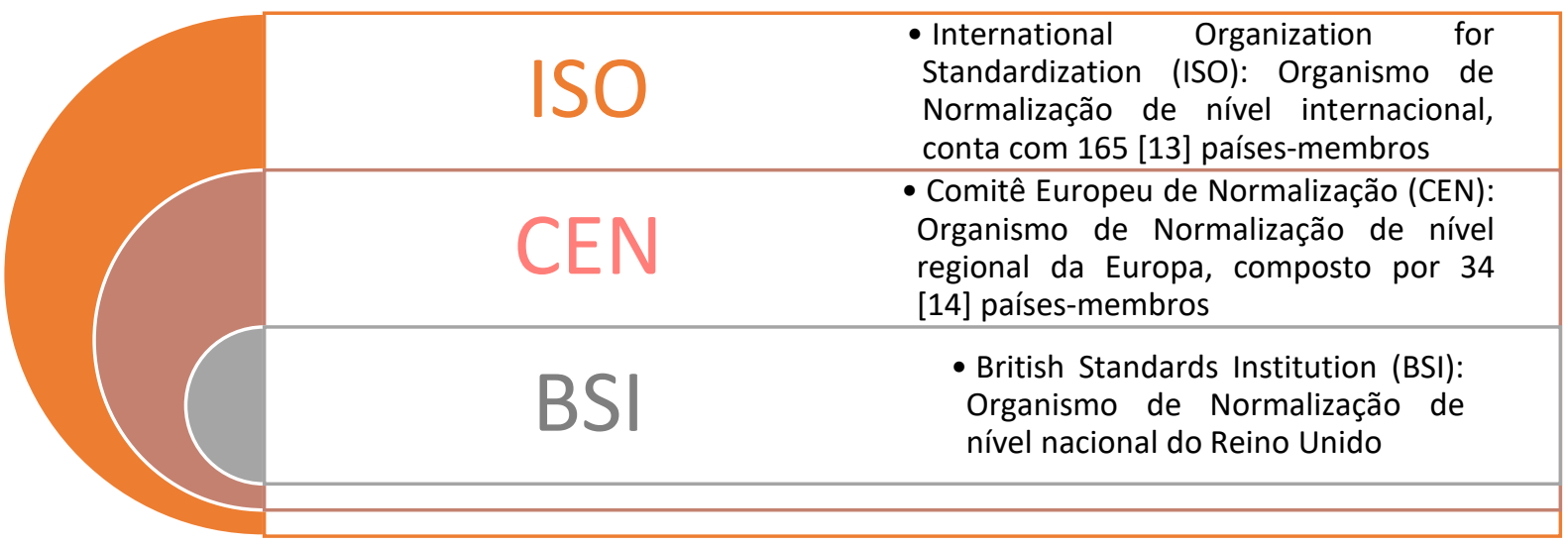

Fonte: as autoras.

Na Europa é determinado pelo CEN, através do Acordo de Viena (Vienna Agreement) [15], que todos seus países membros devem seguir as normas estabelecidas pela ISO. Ambos os organismos trabalham com a aprovação mútua em relação às normas a serem criadas. A CEN deve respeitar integralmente o que é estabelecido pela ISO. A ISO reconhece a autonomia da CEN e engloba necessidades que o comitê europeu possa manifestar em relação a documentos técnicos a serem publicados.

Os demais países citados neste artigo, não-europeus, também são do tipo "membros plenos" da ISO, como a própria os define [13]. Isso significa que eles têm uma participação ativa, tanto política e técnica, no desenvolvimento de normas, podendo inclusive participar das votações diretas. É usual que suas organizações nacionais possam adotar, vender e traduzir as normas ISO, mas não existe uma obrigatoriedade clara. Na América Latina e Ásia-Pacífico também existem organizações regionais, COPANT e PASC respectivamente, mas essas não possuem a mesma relação citada entre CEN e ISO.

\section{STATUS DE ADOÇÃO}

No portal oficial da ISO, Online Browsing Platform (OBP) [16] são encontradas as partes 1, 2, 3 e 5 da ISO 19650 disponibilizadas nas línguas inglesa e francesa. Para membros do Comitê Europeu de Normalização, além desses dois idiomas, também é possível encontrar o texto em alemão [17]. Países membros da ISO, fora da Europa, que tem por idioma principal, ou único, o inglês, disponibilizaram a ISO 19650 na íntegra nos sites de compra pertencentes às organizações normativas atuantes em seus países. Nos países em que essa norma está em processo de tradução ou já traduzida, também existe a possibilidade de adquirir a norma em inglês.

A todos os países membros da ISO é concedida a possibilidade de incluir anexos, a nível nacional. $O$ intuito é que esses anexos venham a abranger especificidades que auxiliem o entendimento e a prática da norma em seus respectivos países. Uma pesquisa feita em [18] com onze nações da Europa apenas quatro afirmaram escrever um Anexo Nacional. Em junho de 2020, um guia foi publicado pela CEN [19], também nos idiomas inglês, francês e alemão, como forma de orientação complementar para as partes $1 \mathrm{e}$ 
2 da ISO 19650. Países de outros continentes ainda não possuem previsão de um documento parecido.

De maneira geral, a própria identificação da nomenclatura das normas ISO, encontrada nos sites das organizações normativas, já esclarece se a norma foi adotada pelo país ou não. Se adotada nacionalmente, a norma passa a ter como primeira sigla as iniciais de sua organização, por exemplo NCh-ISO19650/1:2019 (NCh corresponder à Norma Chilena) ou no caso dos países europeus UNI EN ISO 19650-1:2019 (UNI corresponde à norma italiana e EN à norma europeia vigente na CEN).

O mapa da Figura 2 foi revisado com o detalhamento de status de adoção da ISO 19650 realizado neste estudo (Figura 4). Foram definidos cinco status diferentes para esses países. O levantamento que permitiu a elaboração do mapa está sintetizado no quadro apresentado no Apêndice A deste artigo. As informações do mapa (Figura 4) em relação ao status de adoção da série ISO 19650 são complementadas com o gráfico seguinte (Figura 5), que especifica as iniciativas motrizes dessa adoção.

Atendendo ao objetivo deste artigo, de caracterizar globalmente o processo de adoção das partes 1 e 2 da ISO 19650, na Figura 5 temos uma interligação de informações separadas em eixos sobre a força propulsora de adoção da norma nesses países (governamental, privada ou não identificado). Nesses eixos temos diferentes escalas, a primeira sobre a adoção do BIM segundo os dados da BSI [12], a segunda sobre o status de adoção da ISO 19650 desenvolvida neste estudo.

Figura 4: Status de adoção da ISO 19650

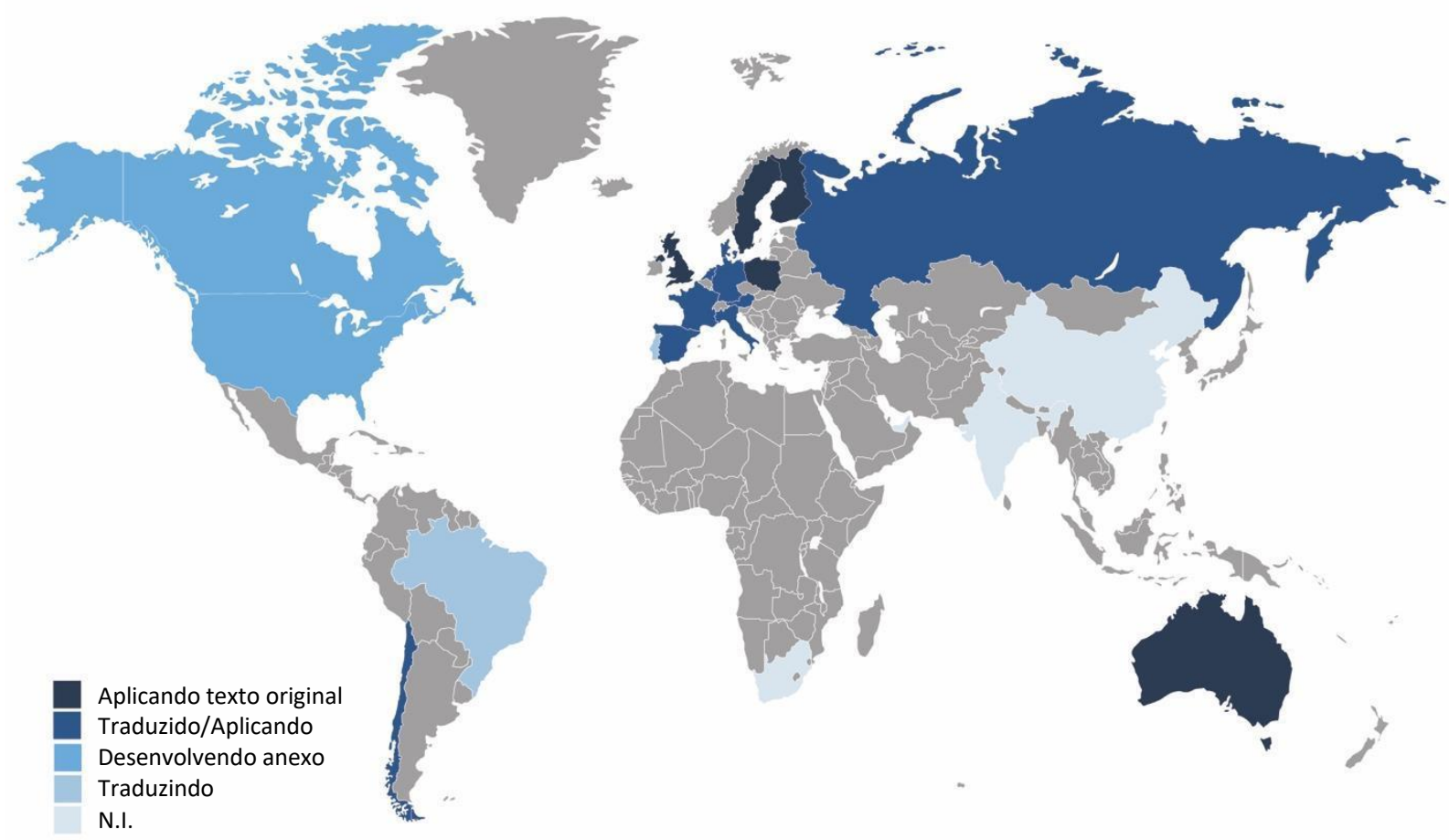

Fonte: as autoras. 


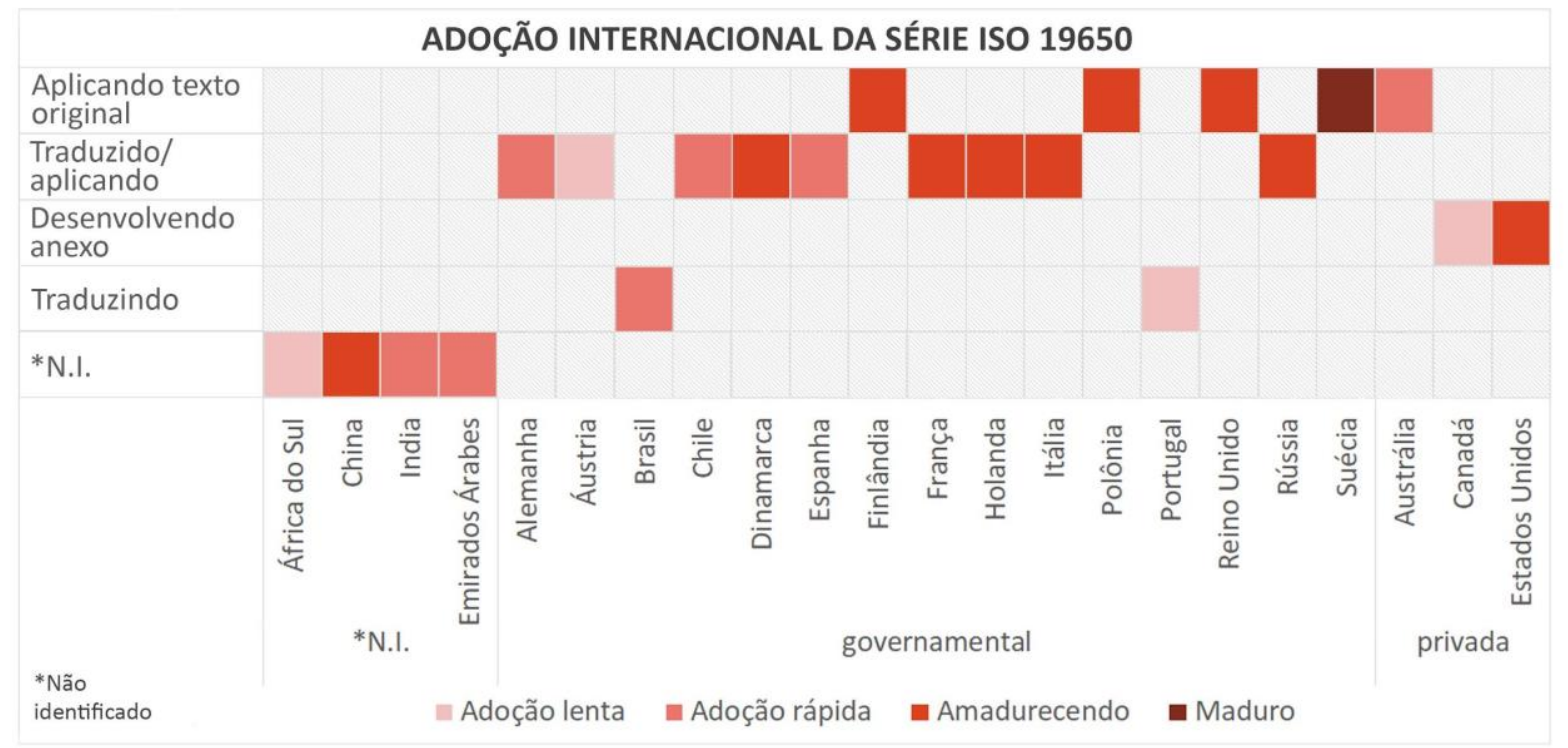

Fonte: as autoras.

É possível observar que as iniciativas do setor governamental são formadas pelo grupo de países europeus, Brasil, Chile, e Rússia, ao passo que as do setor privado são formadas por Austrália, Canadá e Estados Unidos. Logo, podemos inferir que existe um maior empenho na adoção da ISO 19650 por parte da iniciativa governamental. Não foi possível identificar as informações relativas à adoção da ISO 19650 na África do Sul, China, Emirados Árabes e Índia.

A Figura 5 mostra ainda que Brasil (adoção rápida em BIM) e Portugal (adoção lenta) estão traduzindo a norma. Alemanha, Chile, Espanha (adoção rápida), Áustria (adoção lenta), Dinamarca, Holanda, França, Itália e Rússia (amadurecendo em BIM) já traduziram e estão aplicando a norma. Canadá (adoção lenta) e EUA (amadurecendo) estão desenvolvendo anexos. Finlândia, Polônia, Reino Unido (amadurecendo), Suécia (madura) e Austrália (adoção rápida) já estão aplicando a norma em seu texto original.

Além disso, o cruzamento dos dados apresentados na Figura 5 mostraram que o grau de adoção da tecnologia BIM não determina a adoção da norma nos países, como verificado no caso do Canadá (adoção lenta) em processo de desenvolvimento de anexos à ISO 19650, mas pode ser um vetor para aqueles que estão em níveis mais elevados de adoção de BIM, como observado no caso da Suécia (madura em BIM).

\section{CONSIDERAÇÕES FINAIS}

É possível observar que a obrigatoriedade imposta pela CEN, como organismo de normalização regional, teve um papel fundamental para uma aplicação mais rápida da ISO 19650 nos países europeus a partir das iniciativas governamentais. A CEN exige que uma norma seja implementada pelos seus membros em um prazo de até 6 meses depois de sua publicação [20]. Por isso, todos os países europeus pesquisados demonstram em suas webstores que as partes da ISO 19650 estão como classificação 
"vigente" ou outro sinônimo. Estes países, em sua maioria, estão adotando rapidamente ou amadurecendo em BIM.

Visto que a ISO e CEN viabilizam suas normas em inglês, francês e alemão, isso também facilita uma adoção mais rápida para países falantes desses idiomas. A Suécia, Finlândia e Polônia optaram por publicar e aplicar o texto original (em inglês) e não foram encontrados indícios de que iriam traduzi-lo, ao contrário de Portugal que, como encontrado em seu catálogo oficial, atualmente trabalha em uma tradução do documento. O Brasil, país também em processo de tradução, permite constatar que países de língua portuguesa ainda não consolidaram o texto da ISO 19650 em seu idioma.

É válido apontar que países da América, Ásia e África, presentes neste estudo, apesar de fazerem parte de organizações de nível regional (em seus respectivos continentes), essas, por sua vez, não possuem o mesmo engajamento e liderança sobre normas ISO como a CEN, o que contribui para um retardamento da aplicação da norma em estudo.

A partir da caracterização do panorama internacional em relação à adoção da ISO 19650, trazido como resultado desta pesquisa, pôde-se observar complementarmente que o grau de adoção da tecnologia BIM não determina a adoção da norma nos países analisados, mas pode ser um vetor para aqueles que estão em níveis mais elevados de adoção da tecnologia. Quanto à relação status de adoção da ISO 19650 e vetores de disseminação, os resultados apontaram que a maior parte das iniciativas são oriundas do setor governamental.

As referências que embasaram este estudo possibilitaram o entendimento de que as normas técnicas são elementos aliados à difusão da tecnologia BIM, cabendo às instituições normativas de cada país conduzirem este processo, no intuito de alcançar a integração entre projetos e informações.

\section{REFERÊNCIAS}

[1]. KASSEM, M; SUCCAR, B. Macro BIM adoption: Comparative market analysis. Automation in Construction, v. 81, n. 1, p. 286-299, 2017. DOI: https://doi.org/10.1016/j.autcon.2017.04.005

[2]. WEN, Q. et al. The progress and trend of BIM research: A bibliometrics-based visualization analysis. Automation in Construction, v. 124, n. 1, p. 1-15, 2021. DOI: https://doi.org/10.1016/j.autcon.2021.103558

[3]. SHILLCOCK, P. From BS 1192 to ISO 19650 and everything in between. 2019. NBS Enterprises. Disponível em: https://www.thenbs.com/knowledge/from-bs-1192-to-iso19650-and-everything-in-between. Acesso em: 15 novembro 2020.

[4]. INTERNATIONAL ORGANIZATION FOR STANDARDIZATION. ISO 19650:2018. Organization and digitization of information about buildings and civil engineering works, including building information modelling (BIM) - Information management using building information modelling - Part 1: Concepts and principles. Genebra, 2018. Disponível em: https://www.iso.org/standard/68078.html. Acesso em: 15 de novembro de 2020.

[5]. THE BRITISH STANDARDS INSTITUTION (BSI). What happens now that BIM's gone global? 2019. Disponível em: https://www.bsigroup.com/en-GB/blog/BuiltEnvironment-Blog/what-happens-now-that-bims-gone-global/. Acesso em: 10 dezembro 2020. 
[6]. CAREZZATO, G. G. Protocolo de gerenciamento BIM nas fases de contratação, projeto e obra em empreendimentos civis baseado na ISO 19650. 2018. Dissertação (Mestrado em Inovação na Construção Civil) - Escola Politécnica, Universidade de São Paulo, São Paulo, 2018. DOI: https://doi.org/10.11606/D.3.2018.tde-21092018-144640.

[7]. BLAY, K. B.; TUULI, M. M.; FRANCE-MENSAH, J. Managing change in BIM-Level 2 projects: benefits, challenges, and opportunities. Built Environment Project and Asset Management, v. 9, n. 5, pp. 581-596, 2019. DOI: https://doi.org/10.1108/BEPAM-092018-0114.

[8]. BIM WIKI. PAS 1192-2. 2020. Disponível em: https://www.designingbuildings.co.uk/wiki/PAS_1192-2. Acesso em: 14 janeiro 2021.

[9]. MACHADO, F.A.; DELATORRE, J.P.M.; RUSCHEL, R.C. BIM in Latin American Countries: an analysis of regulation evolution. In: SANTOS, E. S; SCHEER, S. (Orgs.). Proceedings of the 18th International Conference on Computing in Civil and Building Engineering. ICCCBE 2020. Lecture Notes in Civil Engineering, v. 98, 2021. DOI: https://doi.org/10.1007/9783-030-51295-8_30

[10]. DE CICCO, R. ISO 19650: going global. 2019. AEC Magazine. Disponível em: https://aecmag.com/technology-mainmenu-35/1752-iso-19650-going-global. Acesso em: 15 novembro 2020.

[11]. SHILLCOCK, P. ISO 19650: When you should adopt it and why. 2019. BIM+. Disponível em: https://www.bimplus.co.uk/analysis/iso-19650-timetableimplementation/\#: :text=and\%20best\%20practice.,The\%20ISO\%2019650\%20series\%20represents\%20the\%20latest\%20industry\%20standa rds\%20and,internationally\%20agreed\%20set\%20of\%20standards. Acesso em: 20 dezembro 2020.

[12]. THE BRITISH STANDARDS INSTITUTION (BSI); UK BIM ALLIANCE. An Introduction to ISO 19650. 2020. (1h51m12s). Disponível em:

https://www.youtube.com/watch?v=Jv307esONdA. Acesso em: 15 novembro 2020.

[13]. INTERNATIONAL ORGANIZATION FOR STANDARDIZATION. About us: Members. Disponível em: https://www.iso.org/members.html. Acesso em: 20 dezembro 2020.

[14]. EUROPEAN COMMITTEE FOR STANDARDIZATION. CEN Comunity: Members. Disponível em: https://standards.cen.eu/dyn/www/f?p=CENWEB:5. Acesso em: 20 de dezembro de 2020.

[15]. INTERNATIONAL ORGANIZATION FOR STANDARDIZATION; EUROPEAN COMMITTEE FOR STANDARDIZATION. AGREEMENT ON TECHNICAL CO-OPERATION BETWEEN ISO AND CEN (Vienna Agreement). 2001. Disponível em: https://isotc.iso.org/livelink/livelink?func=|l\&objld=4230688\&objAction=Open\&nexturl= \%2Flivelink\%2Flivelink\%3Ffunc\%3DIl\%26objld\%3D4230458\%26objAction\%3Dbrowse\%2 6sort\%3Dsubtype. Acesso em: 10 janeiro 2021.

[16]. INTERNATIONAL ORGANIZATION FOR STANDARDIZATION. Online Browsing Platform (OBP). 2020. Disponível em: https://www.iso.org/obp/ui\#home. Acesso em: 22 novembro 2020.

[17]. EUROPEAN COMMITTEE FOR STANDARDIZATION. EN ISO 19650 - 1: 2018. 2018. Disponível em: https://standards.cen.eu/dyn/www/f?p=204:110:0::::FSP_ORG_ID,FSP_LANG_ID:19915 42,25\&cs=1085D2CA41E34A1C2DA860E5234AA5A97. Acesso em: 10 janeiro 2021

[18]. DADMEHR, N.; COATES, S. P. An approach to "National annex to ISO 19650-2". 2019. Disponível em: https://www.researchgate.net/publication/341915122_AN_APPROACH_TO_NATIONAL_ ANNEX_TO_ISO_19650-2. Acesso em: 17 dezembro 2020. 
[19]. EUROPEAN COMMITTEE FOR STANDARDIZATION. Guidance on how to implement EN ISO 19650-1 and -2 in Europe. 2020. Disponível em:

https://standards.cen.eu/dyn/www/f?p=204:110:0::::FSP_ORG_ID,FSP_LANG_ID:19915 42,25\&cs=1085D2CA41E34A1C2DA860E5234AA5A97. Acesso em: 07 janeiro 2021.

[20]. EUROPEAN COMMITTEE FOR STANDARDIZATION. Guidance documents. Disponível em: https://boss.cen.eu/reference-material/guidancedoc/pages/dow/. Acesso em: 07 janeiro 2021.

[21]. THE BRITISH STANDARDS INSTITUTION (BSI); UK BIM ALLIANCE. BIM: A Passport to Global Opportunities and Transformative Collaboration. 2019. (26m41s). Disponível em: https://www.bsigroup.com/en-SE/bim---building-information-modelling---iso19650/. Acesso em: 28 de dezembro de 2020.

[22]. POIRIER, E. A. ISO 19650: A gateway to standardized digital practices to design, deliver and maintain Canada's built environment. 2020. Disponível em: https://www.canbim.com/articles/iso-19650. Acesso em: 08 janeiro 2021.

[23]. BIM FORUM CHILE. Artículo Técnico n. 08: Publicación normas internacionales, ISO19650. Grupo Técnico de Trabajo de Estandarización. 2019. Disponível em: https://bimforum.cl/wp-content/uploads/2019/05/Publicaci\%C3\%B3n-de-normasInternacionales-ISO19650.pdf. Acesso em: 10 janeiro 2021. 


\section{APÊNDICE A}

Quadro 1: Status sobre a tradução da ISO 19650 nos países abordados

\begin{tabular}{|c|c|c|c|c|c|}
\hline PAÍS & BIM ADOPTION [12] & $\begin{array}{c}\text { ORG. } \\
\text { NORM. }\end{array}$ & STATUS & WEBSTORE & INICIATIVA \\
\hline África do Sul & Adoção lenta & SABS & N.I. ${ }^{*}$ & $\begin{array}{l}\text { PARTE } 1 \text { - EN; } \\
\text { PARTE } 2 \text { - EN } ; \\
\text { PARTE } 1 \text { - FR; } \\
\text { PARTE } 2 \text { - FR; }\end{array}$ & - \\
\hline Alemanha & Adoção rápida & DIN & Traduzido/Aplicando & $\begin{array}{l}\text { PARTE 1; } \\
\text { PARTE 2; }\end{array}$ & governamental [10] \\
\hline Austrália & Adoção rápida & AS & $\begin{array}{c}\text { Aplicando texto } \\
\text { original (EN) }\end{array}$ & $\begin{array}{l}\text { PARTE 1; } \\
\text { PARTE 2; }\end{array}$ & privada [10] \\
\hline Áustria & Adoção lenta & ASI & Traduzido/Aplicando & $\begin{array}{l}\text { PARTE 1; } \\
\text { PARTE 2; }\end{array}$ & governamental [10] \\
\hline Brasil & Adoção rápida & ABNT & Traduzindo & $\begin{array}{l}\text { PARTE } 1 \text { - EN } \\
\text { PARTE } 2 \text { - EN }\end{array}$ & governamental [21] \\
\hline Canadá & Adoção lenta & SCC & $\begin{array}{l}\text { Desenvolvendo } \\
\text { anexo }\end{array}$ & $\begin{array}{l}\text { PARTE } 1 \text { - EN; } \\
\text { PARTE } 2 \text { - EN; } \\
\text { PARTE } 1 \text { - FR; } \\
\text { PARTE } 2 \text { - FR; }\end{array}$ & privada [22] \\
\hline Chile & Adoção rápida & INN & Traduzido/Aplicando & $\begin{array}{l}\text { PARTE 1; } \\
\text { PARTE 2; }\end{array}$ & governamental [23] \\
\hline China & Amadurecendo & SAC & N.I.* & WEBSITE & - \\
\hline Dinamarca & Amadurecendo & DS & Traduzido/Aplicando & $\begin{array}{l}\text { PARTE 1; } \\
\text { PARTE 2; }\end{array}$ & governamental [10] \\
\hline $\begin{array}{l}\text { Emirados } \\
\text { Árabes }\end{array}$ & Adoção rápida & ESMA & N.I. ${ }^{*}$ & $\begin{array}{l}\text { PARTE } 1 \text { - EN; } \\
\text { PARTE } 2 \text { - EN; } \\
\text { PARTE } 1 \text { - FR } \\
\text { PARTE } 2 \text { - FR; }\end{array}$ & - \\
\hline Espanha & Adoção rápida & UNE & Traduzido/Aplicando & $\begin{array}{l}\text { PARTE 1; } \\
\text { PARTE 2; }\end{array}$ & governamental [10] \\
\hline Estados Unidos & Amadurecendo & ANSI & $\begin{array}{c}\text { Desenvolvendo } \\
\text { anexo }\end{array}$ & $\begin{array}{l}\text { PARTE 1; } \\
\text { PARTE 2; }\end{array}$ & privada [10] \\
\hline Finlândia & Amadurecendo & SFS & $\begin{array}{c}\text { Aplicando texto } \\
\text { original (EN) }\end{array}$ & $\begin{array}{l}\text { PARTE 1; } \\
\text { PARTE 2; }\end{array}$ & governamental [10] \\
\hline França & Amadurecendo & AFNOR & Traduzido/Aplicando & $\begin{array}{l}\text { PARTE 1; } \\
\text { PARTE 2; }\end{array}$ & governamental [10] \\
\hline Holanda & Amadurecendo & NEN & Traduzido/Aplicando & $\begin{array}{l}\text { PARTE 1; } \\
\text { PARTE 2; }\end{array}$ & governamental [10] \\
\hline India & Adoção rápida & BIS & N.I. & WEBSITE & - \\
\hline Itália & Amadurecendo & UNI & Traduzido/Aplicando & $\begin{array}{l}\text { PARTE 1; } \\
\text { PARTE 2; }\end{array}$ & governamental [10] \\
\hline Polônia & Amadurecendo & PKN & $\begin{array}{c}\text { Aplicando texto } \\
\text { original (EN) }\end{array}$ & $\begin{array}{l}\text { PARTE 1; } \\
\text { PARTE 2; }\end{array}$ & governamental [10] \\
\hline Portugal & Adoção lenta & IPQ & Traduzindo & $\begin{array}{l}\text { CATÁLOGO } \\
\text { PARTE } 1 \text { - EN; } \\
\text { PARTE } 2 \text { - EN; }\end{array}$ & governamental [10] \\
\hline Reino Unido & Amadurecendo & BSI & $\begin{array}{c}\text { Aplicando texto } \\
\text { original (EN) }\end{array}$ & $\begin{array}{l}\text { PACOTE; } \\
\text { PARTE 4; }\end{array}$ & governamental [10] \\
\hline Rússia & Amadurecendo & GOST R & Traduzido/Aplicando & $\begin{array}{l}\text { PARTE 1; } \\
\text { PARTE 2; }\end{array}$ & governamental [10] \\
\hline Suécia & Maduro & SIS & $\begin{array}{c}\text { Aplicando texto } \\
\text { original (EN) }\end{array}$ & $\begin{array}{l}\text { PARTE 1; } \\
\text { PARTE 2; }\end{array}$ & governamental [10] \\
\hline
\end{tabular}

Nota: *N.I. equivale a "Não Identificado"; **link para o catálogo da organização normativa para consulta das demais partes, incluindo as que estão em processo de tradução. Fonte: as autoras. 